\title{
Current treatment of choice for chronic hepatitis $C$ infection
}

This article was published in the following Dove Press journal:

Infection and Drug Resistance

II January 201 I

Number of times this article has been viewed

\author{
Tareq Yasin \\ Thomas R Riley \\ Ian R Schreibman \\ Penn State Hershey Medical \\ Center and College of Medicine, \\ Pennsylvania, USA
}

Correspondence:Thomas Riley Penn State Hershey Gastroenterology, 500 University Drive Hershey, PA 17033, USA

Email triley@hmc.psu.edu
Abstract: More than three million Americans have chronic hepatitis $\mathrm{C}$ infection, and the disease remains one of the most common blood-borne infections in the US. Treatment is focused on the chronic form of the disease, because the acute one tends to be self-limiting. In this article, we review the recent literature regarding the most effective therapy against hepatitis $\mathrm{C}$ infection, to confirm the current treatment of choice for the disease. We conclude that combination therapy with pegylated interferon and ribavirin remains the initial treatment of choice. New research focusing on adjuvant therapies, such as protease and polymerase inhibitors, has yielded early data that appear to be promising.

Keywords: hepatitis $\mathrm{C}$ virus, infection, chronic, treatment, pegylated interferon, ribavirin

\section{Introduction}

Chronic hepatitis $\mathrm{C}$ (HCV) infection continues to be one of the most common bloodborne infections, accounting for approximately $40 \%$ of all chronic liver disease. ${ }^{1,2} \mathrm{Up}$ to $20 \%$ of all $\mathrm{HCV}$-infected individuals develop liver cirrhosis and are at increased risk of developing hepatocellular carcinoma (HCC). Chronic hepatitis $\mathrm{C}$ infection also remains the leading cause of liver transplantation in the US. The Centers for Disease Control (CDC) estimates that approximately 3.2 million Americans are infected with chronic hepatitis $C$, and that an estimated 8000 to 10,000 deaths occur each year because of the disease. ${ }^{1}$ In 2007, 849 cases of confirmed acute hepatitis $\mathrm{C}$ infection were reported in the US but the CDC estimates that approximately 17,000 new HCV infections occurred that year, after adjusting for asymptomatic infection and underreporting. ${ }^{1}$

Since the discovery of the virus in 1989, attention has focused on treating the chronic form of the infection. Acute hepatitis $\mathrm{C}$ is a self-limiting process, but leads to the chronic form of the disease in $75 \%-85 \%$ of cases. ${ }^{3}$

We reviewed the recent literature regarding the most effective therapy for $\mathrm{HCV}$, as well as the current guidelines from the American Association for the Study of Liver Disease (AASLD), National Institutes of Health (NIH), and the CDC to confirm the present treatment of choice for chronic hepatitis $\mathrm{C}$ infection.

The consensus remains that initial combination therapy using pegylated interferon and ribavirin is superior to combination therapy of standard interferon and ribavirin or interferon monotherapy. $3,4,5$ Decisions about who to treat, duration of treatment, and what drugs to use are affected by many factors, including the genotype of the virus, nature and degree of aminotransferase abnormalities, and characteristics seen on liver biopsy. 
Current research regarding the treatment of chronic HCV is focusing on protease inhibitors that interrupt the viral replication cycle. Some protease and polymerase inhibitors have already advanced into clinical trials evaluating their ability to achieve a sustained viral response (SVR), defined as the absence of HCV RNA in serum at the end of treatment and six months later. Initial data appear to be promising. ${ }^{6}$

\section{Role of liver biopsy}

The role of liver biopsy continues to be a controversial topic in the management of chronic hepatitis C. A biopsy reveals important information about the degree of hepatic inflammation, staging of fibrosis, and histopathologic features. Most clinicians still perform a biopsy prior to the initiation of treatment because of its many practical advantages. The AASLD recommends that regardless of the alanine transaminase (ALT) level, a liver biopsy should be performed when the results will influence whether treatment is recommended, but at the same time, a biopsy is not mandatory in order to initiate therapy., In patients with genotype 1, a liver biopsy is usually helpful in deciding whether or not to start treatment. In other cases, such as infection with genotypes 2 or 3 , given the high likelihood of response to treatment, one could argue that there is no need for liver biopsy. A baseline liver biopsy may be helpful in making decisions if patients experience medication side effects and adjustment of treatment is necessary. In addition, a liver biopsy can be used to rule out other liver diseases in the initial workup of patients infected with chronic HCV. ${ }^{4}$ Steatosis and excess hepatocellular iron levels are two common liver biopsy findings that can impede a treatment response. Having one or both of these findings on biopsy is not a contraindication to initiate treatment, but their presence might help in predicting response to treatment. ${ }^{4}$

\section{HCV genotyping}

As part of the initial workup, all patients with chronic $\mathrm{HCV}$ infection should undergo testing to investigate the viral genotype. Genotyping is important in predicting the response to treatment, as well as determining the duration of treatment. ${ }^{11}$ $\mathrm{HCV}$ is an RNA virus with six known genotypes and more than 50 subtypes. ${ }^{8,9,10}$ Genotype 1 is the most common HCV genotype in the US and accounts for three-quarters of all $\mathrm{HCV}$ infections, and remains the most difficult type to treat. Genotypes 2 and 3 account for most of the other genotypes in the US, and genotype 4 remains prevalent in Egypt. Once the genotype is identified, there is no value in rechecking it, because the likelihood of coinfection with multiple genotypes is rare.

\section{Goals of treatment}

The majority of patients acutely infected with HCV are either asymptomatic or develop mild symptoms such as fevers, fatigue, joint pain, nausea, and vomiting, and therefore do not seek medical attention. However, $75 \%-85 \%$ of those infected with acute hepatitis $\mathrm{C}$ will remain $\mathrm{HCV}$-infected, with the majority also developing chronic liver disease. ${ }^{3}$ Up to $20 \%$ of chronic HCV-infected patients are reported to develop cirrhosis over a period of 20-30 years. It is because of the cirrhosis, and the more feared complication of HCC, as well as other intraand extrahepatic manifestations of chronic HCV infection, that treatment is recommended for most patients with $\mathrm{HCV}$ infection. The goal of treatment is eradication of the virus to prevent the complications associated with the disease. ${ }^{4}$

\section{Ribavirin monotherapy}

Ribavirin is a nucleoside analog that inhibits replication of RNA viruses by inhibiting the initiation and elongation of RNA fragments, resulting in inhibition of viral protein synthesis. Ribavirin appears to inhibit hepatitis $\mathrm{C}$ viral infectivity in a dose-dependent manner. ${ }^{11}$ Several trials have evaluated the use of ribavirin as monotherapy for chronic hepatitis $\mathrm{C}$ infection. Brok et al performed a meta-analysis of 11 trials and concluded that, when used alone, ribavirin is ineffective in achieving an SVR, and patients who are intolerant of interferon should not continue treatment with ribavirin alone. $^{11}$

In a randomized, double-blind, placebo-controlled trial by Di Bisceglie et al, 58 patients were randomly assigned to receive oral ribavirin or placebo for one year. They found that ribavirin had beneficial effects on serum aminotransferase levels and histologic findings on liver biopsy in patients with chronic hepatitis $\mathrm{C}$ infection. However, these effects were not accompanied by changes in HCV RNA levels, and were not sustained when ribavirin therapy was discontinued. ${ }^{12,13}$ Thus, when used alone, even for periods as long as one year, ribavirin is unlikely to be of value as monotherapy for chronic hepatitis $\mathrm{C}$.

\section{Pegylated versus regular interferon monotherapy}

Pegylation of interferon, ie, the covalent attachment of polyethylene glycol polymer chains to another molecule, in this case interferon, results in an increase in the hydrodynamic size of the drug which, in turn, prolongs its circulatory time by reducing renal clearance, and decreases the immunogenicity of the drug. There are two forms of peginterferon approved by the Food and Drug Administration (FDA) in the US, 
ie, the $40 \mathrm{kDa}$ peginterferon alfa-2a (Pegasys ${ }^{\circledR}$, Hoffmann-La Roche, Nutley, NJ) and $12 \mathrm{kDa}$ peginterferon alfa-2b (PegIntron $^{\circledR}$, Schering-Plough Corporation, Kenilworth, NJ).

When used as monotherapy, interferon (whether pegylated or not), has better outcomes than ribavirin alone. Peginterferon monotherapy is associated with higher rates of SVR compared with standard interferon. ${ }^{14}$ SVR rates are $~ 25 \%$ for patients with HCV genotype 1 (compared with $8 \%-12 \%$ with standard interferon) and 54\% for those with genotypes 2 and 3 (compared with $\sim 34 \%$ for standard interferon).

Multiple studies were done to compare treatment of $\mathrm{HCV}$ using nonpegylated interferon versus the pegylated form of the drug., ${ }^{9,10,14}$ These studies revealed that peginterferon is superior to and as safe as interferon for the initial treatment of adult patients with compensated chronic hepatitis $\mathrm{C}$. In a randomized, double-blind trial comparing pegylated interferon alfa- $2 \mathrm{~b}$ with standard interferon alfa- $2 \mathrm{~b}$, patients were randomly assigned to one of four treatment groups. ${ }^{14}$ Three groups were treated with peginterferon alfa- $2 \mathrm{~b}(0.5$, 1.0 , or $1.5 \mu \mathrm{g} / \mathrm{kg}$ subcutaneously once weekly) and one group was treated with standard interferon alfa- $2 \mathrm{~b}$ (3 MU subcutaneously three times per week). The results of the study revealed that the end-of-treatment viral response for peginterferon alfa- $2 b$ was dose-related. An increase in the dose of peginterferon alfa- $2 \mathrm{~b}(0.5,1.0$, and $1.5 \mu \mathrm{g} / \mathrm{kg})$ was associated with an increase in the viral response rate $(33 \%$, $41 \%$, and $49 \%$, respectively). All three peginterferon alfa- $2 \mathrm{~b}$ dose groups had significantly higher proportions $(P<0.01)$ of patients with an end-of-treatment viral response compared with the standard interferon alfa-2b group (24\%). ${ }^{14}$

While combination therapy with peginterferon and ribavirin remains the optimal initial treatment for $\mathrm{HCV}$ patients as detailed below, there are certain populations in which treatment with ribavirin is contraindicated, leaving peginterferon monotherapy as the primary choice of treatment. ${ }^{3}$ Such is true in patients with renal disease, especially those requiring hemodialysis. Ribavirin is not recommended for patients who have a creatinine clearance below $50 \mathrm{~mL} / \mathrm{min}$. Ribavirin is also not cleared by dialysis, and in those individuals with end-stage renal disease the drug may accumulate and cause dose-dependent hemolytic anemia. Initial pilot studies have indicated that ribavirin can cause severe hemolysis, and a number of other small studies have indicated that ribavirin levels have to be monitored very closely if used in this subpopulation.

\section{Combination therapy}

Combination therapy of peginterferon alfa and ribavirin continues to be the optimal initial treatment for $\mathrm{HCV}$ on the basis of the findings of three major trials (see Figure 1). The first trial, carried out by Manns et al included 1530 patients with chronic hepatitis $\mathrm{C}$ who were assigned to one of three treatment arms. ${ }^{15}$ The first arm received interferon alfa- $2 b$ (3 MU subcutaneously three times per week) and ribavirin $1000-1200 \mathrm{mg} /$ day. The second arm received peginterferon alfa- $2 \mathrm{~b}(1.5 \mu \mathrm{g} / \mathrm{kg} /$ week $)$ and $800 \mathrm{mg} /$ day ribavirin, while the third arm received peginterferon alfa- $2 \mathrm{~b}(1.5 \mu \mathrm{g} / \mathrm{kg} /$ week for four weeks then $0.5 \mu \mathrm{g} / \mathrm{kg} /$ week) and ribavirin 1000-1200 $\mathrm{mg} / \mathrm{day}$, for a total of 48 weeks. The results of this trial showed that the SVR rate was significantly higher in the higher-dose peginterferon group (54\%) than in the lower-dose peginterferon $(47 \%)$ or interferon (47\%) groups. Among patients with HCV genotype 1 infection, the corresponding SVR rates were $42 \%, 34 \%$, and $33 \%$. The SVR rate for patients with genotypes 2 and 3 infection was about $80 \%$ for all treatment groups. This demonstrated that the most effective therapy is the combination of peginterferon alfa- $2 \mathrm{~b} 1.5 \mu \mathrm{g} / \mathrm{kg} /$ week and ribavirin, with the most benefit seen in patients with $\mathrm{HCV}$ genotype 1 infection. In addition, the study found that the side effects seen with the peginterferon alfa- $2 b$ and ribavirin combination were similar to those with interferon alfa- $2 b$ and ribavirin. There was an increase in influenza-like effects with the peginterferon, although the authors related that to the higher dose of peginterferon used in the trial.

The second trial by Fried et al was a multicenter study that involved 1121 patients who were randomly assigned to one of three treatment groups. ${ }^{16}$ One group received combined treatment with peginterferon alfa- $2 \mathrm{a} 180 \mu \mathrm{g}$ once per week and ribavirin 1000-1200 mg/day. The second group received peginterferon alfa- $2 \mathrm{a} 180 \mu \mathrm{g}$ once per week and placebo (peginterferon alfa-2a monotherapy). The third group received interferon alfa- $2 \mathrm{~b}$ ( $3 \mathrm{MU}$ subcutaneously three times per week) and ribavirin 1000-1200 mg/day. The treatment duration was 48 weeks.

As with the combination therapy trial involving peginterferon alfa- $2 \mathrm{~b}$ and ribavirin, this study also found that a higher rate of SVR was achieved in patients who received peginterferon alfa-2a and ribavirin than in those who received interferon alfa- $2 \mathrm{~b}$ and ribavirin ( $56 \%$ versus $44 \%$, respectively) or peginterferon alfa-2a monotherapy ( $56 \%$ versus $29 \%$ ).

The third investigation was a randomized, double-blind, multicenter trial by Hadziyannis et al who evaluated 1311 patients with chronic hepatitis $\mathrm{C}$, with the objective of assessing the efficacy and safety of 24 versus 48 weeks of combination treatment with peginterferon alfa-2a (180 $\mu \mathrm{g}$ per week) and ribavirin at a low dose $(800 \mathrm{mg} /$ day $)$ or as a standard weight-based dose (1000-1200 mg/day). ${ }^{17}$ 


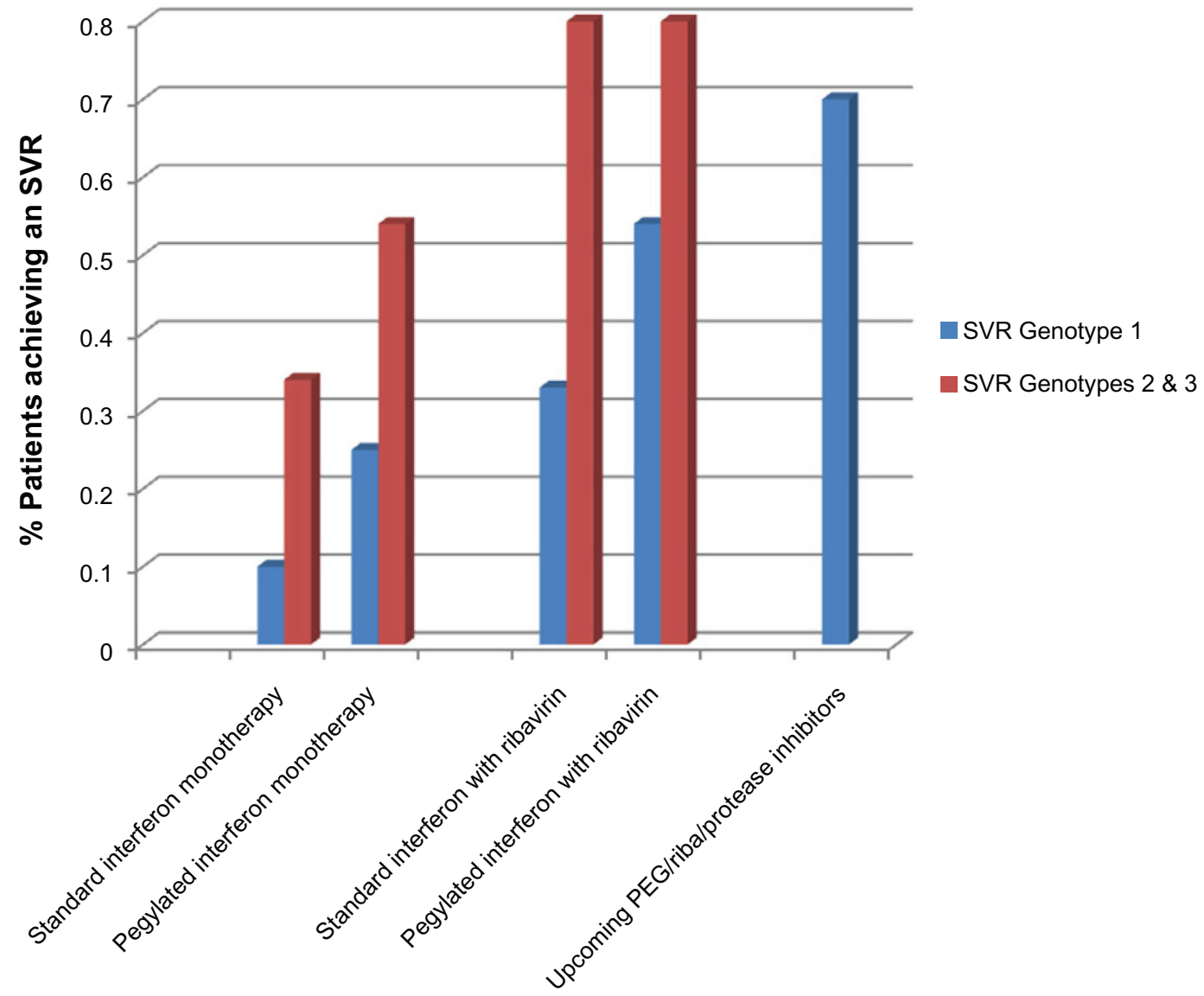

Figure I Likelihood of achieving a sustained viral response with different modalities of treatment, for hepatitis C virus genotype I and genotypes 2 and 3 . Abbreviation: SVR, sustained viral response.

The study found that, overall, in patients infected with HCV genotype 1, treatment for 48 weeks was statistically superior to that for 24 weeks, and that standard-dose ribavirin (1000-1200 mg/day) was statistically superior to low-dose ribavirin. However, the trial also found that in patients with HCV genotypes 2 and 3, the SVR was not statistically different in any of the treatment groups. Based on the results of this study, the current recommended treatment for patient with chronic hepatitis $\mathrm{C}$ infection genotype 2 or 3 is peginterferon with lower-dose ribavirin $(800 \mathrm{mg} /$ day $)$ for 24 weeks only.

\section{Peginterferon alfa-2a versus peginterferon alfa-2b}

The few head-to-head comparisons done thus far for the two forms of pegylated interferon have found that SVR rates are not significantly different. In the COMPARE trial, Silva et al randomized 36 patients to two treatment groups, one receiving peginterferon alfa- $2 \mathrm{~b}(1.5 \mu \mathrm{g} / \mathrm{kg} /$ week $)$ and the other receiving peginterferon alfa- $2 \mathrm{a}(180 \mu \mathrm{g} /$ week $)$ for four weeks, and then added ribavirin $(13 \mathrm{mg} / \mathrm{kg} /$ day) for an additional four weeks to each group. ${ }^{18}$ The pharmacokinetic profile,
mRNA expression of interferon-induced gene transcripts, and HCV RNA levels, were measured. The study results showed that patients treated with peginterferon alfa- $2 b$ had a greater upregulation of peginterferon alfa response genes and a greater decrease in HCV RNA measured at one and four weeks than patients receiving peginterferon alfa- $2 \mathrm{a}$. However, the study did not include measurement of the SVR for each group, and the duration of treatment was not the recommended 48 weeks.

A study by Di Bisceglie et al compared the two forms of the drug. ${ }^{19}$ In this randomized, prospective, open-label trial, 380 patients infected with HCV genotype 1 with high viral loads were allocated to one of two treatment arms. One arm received peginterferon alfa- $2 \mathrm{a}(180 \mu \mathrm{g} /$ week $)$ and ribavirin 1000-1200 mg, while the other arm received peginterferon alfa- $2 \mathrm{~b}(1.5 \mu \mathrm{g} / \mathrm{kg} /$ week $)$ and ribavirin $1000-1200 \mathrm{mg}$ for 12 weeks. Drug levels were measured before treatment and weekly during the first week through to week 12 . The viral response was also measured at week 12 and at the end of the study. HCV RNA levels were comparable between the two groups, with no significant difference at any point in time during the study. The proportion of patients with an early 
viral response (EVR) was similar between the two arms (66\% versus $63 \%$, respectively). In addition, there was no difference between the groups for those with a rapid viral response (RVR), defined as an undetectable serum HCV RNA level after four weeks of treatment. The investigators concluded that the two peginterferon preparations showed comparable anti-HCV activity during the first 12 weeks of treatment.

A third trial compared the same two drug formulations in the treatment of HCV infection in a subpopulation of patients coinfected with HIV, and the results again showed no significant differences in the efficacy and safety of the two forms of the drug. ${ }^{20}$

In a more recent study by McHutchison et al involving 118 centers, 3070 patients infected with HCV genotype 1 were randomly assigned to one of three treatment groups. ${ }^{21}$ The first group was treated with a combination of peginterferon alfa- $2 \mathrm{~b}$ at a standard dose of $1.5 \mu \mathrm{g} / \mathrm{kg} /$ week and ribavirin at a dose of 800-1400 mg/day. The second group was treated with peginterferon alfa- $2 \mathrm{~b}$ at a low dose of $1.0 \mu \mathrm{g} / \mathrm{kg}$ / week and ribavirin $800-1400 \mathrm{mg} /$ day. The third group was treated with peginterferon alfa- $2 \mathrm{a} 180 \mu \mathrm{g} /$ week and ribavirin 1000-1200 mg/day. Each of the three groups completed 48 weeks of treatment. The investigators compared SVR rates and the safety profiles of the peginterferon alfa- $2 b$ regimens and the standard-dose peginterferon alfa- $2 \mathrm{a}$ and peginterferon alfa- $2 b$ regimens. SVR rates were similar for the three regimens, ie, $39.8 \%$ for standard-dose peginterferon alfa- $2 \mathrm{~b}$, $38.0 \%$ for low-dose peginterferon alfa- $2 \mathrm{~b}$, and $40.9 \%$ for peginterferon alfa-2a $(P=0.20$ for standard dose versus low-dose peginterferon alfa- $2 \mathrm{~b} ; P=0.57$ for standard-dose peginterferon alfa- $2 b$ versus peginterferon alfa- $2 a$ ). In addition, McHutchison et al reported that the safety profile was similar among the three groups. The study concluded that in patients infected with the HCV genotype 1, SVR and tolerability rates did not differ significantly between the two available peginterferon-ribavirin regimens or between the two doses of peginterferon alfa-2b. ${ }^{21}$

Another recent study by Ascione et al revealed a difference between the two forms of peginterferon in 320 consecutive, treatment-naive, HCV RNA-positive patients with chronic hepatitis. They randomly assigned these patients to once-weekly peginterferon alfa-2a (180 $\mu \mathrm{g}$, Group A) or peginterferon alfa-2b $(1.5 \mu \mathrm{g} / \mathrm{kg}$, Group B) and ribavirin $1000 \mathrm{mg} /$ day (body weight $<75 \mathrm{~kg}$ ) or $1200 \mathrm{mg} /$ day (body weight $>75 \mathrm{~kg}$ ) for 48 weeks (genotypes 1 and 4 ) or 24 weeks (genotypes 2 and 3.) The primary endpoint was SVR. More patients in Group A than Group B achieved an SVR
(110/160 [68.8\%] versus 87/160 [54.4\%]; $P=0.008)$, with baseline HCV RNA levels > 500,000 IU/mL (58/84 [69\%] versus 43/93 [46.2\%]; $P=0.002$ ). However, the SVR rates in groups $\mathrm{A}$ and $\mathrm{B}$ were not statistically different in patients with baseline HCV RNA < 500,000 IU/mL (52/76 [68.4\%] versus $44 / 67$ [65.7\%]; $P=0.727$ ) or in patients with cirrhosis (14/33 [42.4\%] versus $12 / 26[46.1 \%] ; P=0.774) .{ }^{22}$

\section{Predictors of treatment response}

Several pretreatment characteristics, as well as an early response to treatment, contribute to the likelihood of eradicating $\mathrm{HCV}$ infection and achieving an SVR. The viral genotype continues to be one of the strongest predictors of response. ${ }^{4,53}$ Patients infected with HCV genotype 1, which is the most common genotype in the US, continue to be those in whom an SVR is most difficult to achieve and who require the longest duration of treatment. On the other hand, those with genotypes 2 or 3 tend to have an EVR and should be treated with a combination of peginterferon and lower-dose ribavirin for a period of 24 weeks only.

Lower pretreatment HCV RNA levels (less than two million copies per $\mathrm{mL}$ ) also correlate with better SVR rates. ${ }^{21}$ In addition, age younger than 40 years, absence of bridging fibrosis or cirrhosis on liver biopsy, absence of steatosis, and body weight less than $75 \mathrm{~kg}$ were all favorable pretreatment characteristics for achieving an SVR. ${ }^{24,25}$

More recent studies have been investigating whether RVR, defined as the absence of HCV RNA after four weeks of treatment with peginterferon and ribavirin, can be used as a marker to determine the duration of treatment. A retrospective analysis of data from the trial by Hadziyannis et al showed that if an RVR is achieved, the likelihood of achieving an SVR was $89 \%-90 \%$ at both 24 and 48 weeks of treatment. ${ }^{17}$ In a second prospective study, Ferenci et al investigated whether the same applies for $\mathrm{HCV}$ genotypes 1 and $4 .{ }^{26}$ Patients in this study received a combination of peginterferon alfa-2a $180 \mu \mathrm{g} /$ week and ribavirin 1000-1200 mg/day. The patients who achieved an RVR by week 4 were assigned to complete 24 weeks of treatment. Of 516 patients included in the study, 150 had an RVR and 143 completed the 24 weeks of treatment. The study found that patients who achieved an RVR differed significantly from those without an RVR, in that patients with RVR were leaner, had lower pretreatment HCV RNA levels, and had lower baseline ALT levels. The study also showed that patients with genotype 1 or 4 , who achieved an RVR, had an overall SVR of $80.4 \%$ after only 24 weeks of treatment. 


\section{Retreatment of nonresponders and relapsers}

There are no clear guidelines regarding retreatment of patients who either never achieve an SVR (nonresponders) or those who relapse after an initial response to treatment. The approach to these patients should depend on the type of initial treatment they received, their previous type of response to that treatment, their viral genotype, and the severity of underlying liver disease. The AASLD recommends retreatment with a combination of peginterferon and ribavirin for nonresponders or relapsers who have significant fibrosis or compensated cirrhosis, and who have undergone previous regimens of treatment using nonpegylated interferon. ${ }^{4}$ However, for those patients who have failed to respond to the pegylated interferon and ribavirin combination regimen, retreatment to eradicate the disease is not recommended, even if a different type of pegylated interferon is used.

Krawitt et al investigated 182 patients who had previously failed to achieve an SVR at 24 weeks following a multiweek course of treatment with either interferon monotherapy or interferon in combination with ribavirin, and were then treated with a combination of pegylated interferon alfa- $2 \mathrm{~b}(100 \mu \mathrm{g} /$ week for those of body weight $<75 \mathrm{~kg}$ and $150 \mu \mathrm{g} /$ week for those of body weight $>75 \mathrm{~kg}$ ) and ribavirin $1000 \mathrm{mg} /$ day. ${ }^{27}$ The patients were treated for 24 weeks, at which time an HCV RNA level was measured. If the HCV RNA levels were undetectable, treatment was continued for 24 more weeks for a total of 48 weeks. If HCV RNA levels were detectable, treatment was discontinued. The results of this study showed that SVR was achieved in $20 \%$ of previous nonresponders and $55 \%$ of previous relapsers. Within the previous nonresponders group, the SVR of those with genotype 1 was $17 \%$ compared with $57 \%$ in those with genotypes 2 or 3 , although this difference was not statistically significant. ${ }^{27}$ The study concluded that the response to the combination of pegylated interferon and ribavirin in previous nonresponders with genotypes 2 and 3 and in prior relapsers is comparable with the overall rates of SVR in previously untreated patients.

\section{Special populations}

Of all the HIV-infected individuals worldwide, 25\%-30\% have chronic $\mathrm{HCV}$ coinfection. The consequences of such coinfection include accelerated progression of liver disease, higher rates of morbidity and mortality, and shortened lifespan following hepatic decompensation. ${ }^{28}$ Factors contributing to such deleterious consequences include higher HCV viral loads and possibly replication of $\mathrm{HCV}$ at extrahepatic sites, including in dendritic cells, peripheral blood mononuclear cells, and monocytes. ${ }^{29}$ Therefore, HCV/HIV coinfected patients present challenging issues for treatment.

One of the first decisions to be addressed in the coinfected individual is which infection should be treated first. That usually depends on the relative stage of each disease. ${ }^{28}$ In those individuals who do not require antiretroviral therapy for HIV, treatment of HCV should be the first priority. ${ }^{30}$ However, in individuals with AIDS and CD4 counts $<200$, antiretroviral therapy and prophylaxis should be started first. HCV treatment should be initiated when the CD4 counts recover. In patients with a history of recurrent drug-induced hepatotoxicity and an inability to tolerate antiretroviral therapy, $\mathrm{HCV}$ treatment should be initiated first.

The primary goal of therapy in HIV/HCV coinfected patients remains the same as for those with HCV infection, ie, achieving an SVR. Secondary goals of treatment include reducing fibrosis and necroinflammatory activity. ${ }^{28}$ The treatment of choice for such individuals remains the combination of pegylated interferon and ribavirin. In the AIDS Pegasys Ribavirin International Coinfection Trial (APRICOT), Torriani et al showed that patients treated with the combination of peginterferon alfa-2a and ribavirin had an SVR of $40 \%$ compared with $20 \%$ in those treated with a combination of peginterferon alfa- $2 \mathrm{a}$ and placebo and $12 \%$ in those who received a combination of standard interferon and ribavirin. ${ }^{31}$

Some studies have shown that 3-hydroxy-3-methylglutarylcoenzyme A (HMC-CoA) reductase inhibitors play a role in in vitro $\mathrm{HCV}$ viral replication. Milazzo et al have published results of a randomized, open-label study in which 44 patients coinfected with $\mathrm{HIV} / \mathrm{HCV}$ were randomized to receive either a peginterferon alfa- $2 \mathrm{~b}$ and ribavirin combination or a triple combination of peginterferon alfa- $2 b$, ribavirin, and fluvastatin. The primary endpoint of the study was SVR and the secondary endpoint was RVR. The results of this study revealed that addition of fluvastatin to standard therapy did not significantly increase SVR rates but did significantly improve RVR rates. ${ }^{32}$

Another special population of $\mathrm{HCV}$-infected individuals is those using illicit intravenous drugs. According to the AASLD, decisions regarding $\mathrm{HCV}$ treatment in this group should be made on a case-by-case basis, considering the anticipated risks and benefits. Treatment should not be withheld from persons who currently use illicit drugs or who are on a methadone maintenance program, provided that they are able and willing to maintain close monitoring and practice contraception. ${ }^{4}$

In addition, the AASLD reports that antiviral treatment is contraindicated in solid organ (lung, heart, or renal) transplant 
recipients, those with uncontrolled major depressive disorder, autoimmune hepatitis, or other conditions that might be exacerbated by interferon and ribavirin, and those who are pregnant, or are unwilling or unable to practice adequate contraception. ${ }^{4}$

\section{Side effects}

Side effects of treatment of chronic hepatitis $\mathrm{C}$ infection remain a major reason of discontinuation, and drug intolerance is an important factor in noncompliance with treatment. Side effects occur in $>20 \%$ of patients treated with pegylated interferon and ribavirin. Hematologic side effects are common, and include significant anemia, the cause of which is thought to be multifactorial, including bone marrow suppression from the interferon as well as ribavirin-induced hemolysis. The side effects of ribavirin seem to be doserelated, because the drug is concentrated in red blood cells resulting in a relative deficiency of adenosine triphosphate in erythrocytes, which increases their susceptibility to oxidative damage and hemolysis.

Interferon can affect the bone marrow and may lead to suppression, neutropenia, and thrombocytopenia. This becomes significant especially when dealing with cirrhotic patients who have underlying thrombocytopenia secondary to liver disease. Other side effects of interferon include fevers, headaches, arthralgias, myalgias, fatigue, and rigors, all of which tend to occur in the first few weeks of treatment and improve as treatment continues. Decreased appetite, weight loss, alopecia, and insomnia have also been described as side effects of interferon.

Depression and other neuropsychiatric side effects, such as apathy and irritability, can be seen in up to $20 \%$ of patients treated with interferon. Suicide has also been reported in some patients treated with interferon and the AASLD now considers uncontrolled major depressive disorder as a contraindication to treatment. ${ }^{4}$

In a prospective case-control study, Huang et al recruited 70 patients with chronic $\mathrm{HCV}$ who were $\geq 65$ years of age for active treatment (Group A) and an additional 140 sex- and HCV genotype-matched patients who were 50-64 years of age as a control group (Group B). All patients were allocated to receive a combination of peginterferon alfa- $2 \mathrm{a}$ and ribavirin, with SVR as the primary endpoint. Patients were also monitored biweekly at outpatient visits during the first month, and then monthly thereafter for evaluation of drug safety. In addition, biochemical and hematologic tests were performed. Adverse events were graded as mild, moderate, severe, or potentially life-threatening. Group A was found to have a significantly higher rate of treatment discontinuation (21.4\% versus $6.4 \% ; P=0.001)$ and adverse events $(34.3 \%$ versus $20 \% ; P=0.002)$ than Group $B$. In addition, SVR rate was substantially lower in Group A than in Group B. Therefore, in this study, older patients with HCV infection had a greater frequency of adverse events and poorer adherence to peginterferon and ribavirin..$^{33}$

\section{Future of HCV treatment}

Current research on treatment for chronic $\mathrm{HCV}$ is focused on the protease inhibitors. ${ }^{6}$ Protease and polymerase inhibitors interrupt the cycle of viral replication. Some protease and polymerase inhibitors have already advanced into clinical trials for evaluation of their effect on achieving an SVR. Initial studies are showing that, when used in combination with the pegylated interferon and ribavirin, there is the potential to achieve an SVR in up to $70 \%$ of individuals with HCV genotype 1 infection compared with the current likelihood of achieving an SVR of $50 \%$ with combination therapy alone. ${ }^{34}$

\section{Summary}

The goal of treatment for chronic hepatitis $\mathrm{C}$ infection is eradication of the virus to prevent its complications, including chronic liver disease, cirrhosis, HCC, and extrahepatic manifestations. Eradication of the disease is measured by the SVR. Predictors of achieving an SVR are the viral genotype (with genotype 2 and 3 having a better prognosis than genotype 1), low HVC RNA load (less than two million copies/ $\mathrm{mL}$ ), age younger than 40 years, absence of bridging fibrosis or cirrhosis on liver biopsy, absence of steatosis, and body weight less than $75 \mathrm{~kg}$.

The current treatment of choice for chronic HCV infection is a combination of pegylated interferon alfa and ribavirin. The RVR as well as the EVR can be used to predict the likelihood of achieving an SVR once treatment is initiated. The current recommended duration of treatment for patients infected with the HCV genotype 1 is 48 weeks. If patients do not achieve an EVR, the recommendation would then be to stop treatment. For patients infected with $\mathrm{HCV}$ genotype 2 or 3 , the recommended duration of treatment is 24 weeks rather than 48 weeks, and a lower dose of ribavirin can be used. Retreatment of nonresponders and relapsers should depend on the initial medication regimen, the previous response to that treatment, viral genotype, and the severity of the underlying liver disease.

\section{Disclosure}

IS is on the speaker's bureau for Roche and Schering Plough. TR and TY have no affiliations. 


\section{References}

1. Centers for Disease Control. Public Health Service inter-agency guidelines for screening donors of blood, plasma, organs, tissues, and semen for evidence of hepatitis B and hepatitis C. MMWR Recomm Rep. 1991;40(No. RR-4):1-17.

2. Alter MJ. Epidemiology of hepatitis C. Hepatology. 1997;26:62S-5S.

3. The National Institutes of Health Consensus Statement on Management of Hepatitis C: 2002. NIH consensus and State-of-the-Science Statements. Volume 19, Number 3, June 10-12, 2002.

4. Strader, DB, Wright, T, Thomas, DL, Seeff, LB; American Association for the Study of Liver Diseases. Diagnosis, management, and treatment of hepatitis C. Hepatology. 2004;39:1147.

5. The National Institutes of Health Consensus Development Conference. Management of hepatitis C. Hepatology. 1997;26 Suppl 1:1S.

6. Reesink H, Bergmann J, de Bruijne J, and others. Safety and antiviral activity of SCH 900518 administered as monotherapy and in combination with peginterferon alfa- $2 \mathrm{~b}$ to naive and treatment-experienced $\mathrm{HCV}$ infected patients. 44th Annual Meeting of the European Association for the Study of the Liver (EASL 2009). Copenhagen, Denmark. April 22-26, 2009. Abstract 86.

7. Perrillo RP. The role of liver biopsy in hepatitis C. Hepatology. 1997;26:57.

8. Fried MW, Shiffman, ML, Reddy KR, et al. Peginterferon alfa-2a plus ribavirin for chronic hepatitis $\mathrm{C}$ virus infection. $N$ Engl $J$ Med. 2002;347:975

9. Hadziyannis SJ, Sette H Jr, Morgan TR, et al. Peginterferon-alpha2a and ribavirin combination therapy in chronic hepatitis $\mathrm{C}$ : a randomized study of treatment duration and ribavirin dose. Ann Intern Med. 2004; $140: 346$.

10. Manns MP, McHutchison JG, Gordon SC, et al. Peginterferon alfa-2b plus ribavirin compared with interferon alfa- $2 \mathrm{~b}$ plus ribavirin for initial treatment of chronic hepatitis C: A randomised trial. Lancet. 2001;358:958.

11. Brok J, Gluud LL, Gluud C. Ribavirin monotherapy for chronic hepatitis C. Cochrane Database Syst Rev 2009, Issue 4. Art. No.: CD005527. DOI: 10.1002/14651858.CD005527.pub2.

12. Di Bisceglie AM, Conjeevaram HS, Fried MW, et al. Ribavirin as therapy for chronic hepatitis C. A randomized, double-blind, placebo-controlled trial. Ann Intern Med. 1995;123:897.

13. Pawlotsky JM, Dahari H, Neumann AU, et al. Antiviral action of ribavirin in chronic hepatitis C. Gastroenterology. 2004;126:703.

14. Lindsay KL, Trepo C, Heintges T, et al. A randomized, double-blind trial comparing pegylated interferon alfa- $2 \mathrm{~b}$ to interferon alfa- $2 \mathrm{~b}$ as initial treatment for chronic hepatitis C. Hepatology. 2001; 34:395.

15. Manns MP, McHutchison JG, Gordon SC, et al. Peginterferon alfa-2b plus ribavirin compared with interferon alfa- $2 \mathrm{~b}$ plus ribavirin for initial treatment of chronic hepatitis C: A randomised trial. Lancet. 2001;358:958

16. Fried MW, Shiffman ML, Reddy KR, et al. Peginterferon alfa-2a plus ribavirin for chronic hepatitis $\mathrm{C}$ virus infection. $N$ Engl $J$ Med. 2002;347:975.

17. Hadziyannis SJ, Sette H Jr, Morgan TR, et al. Peginterferon-alpha2a and ribavirin combination therapy inchronic hepatitis $\mathrm{C}$ : a randomized study of treatment duration and ribavirin dose. Ann Intern Med. 2004; $140: 346$

Infection and Drug Resistance

\section{Publish your work in this journal}

Infection and Drug Resistance is an international, peer-reviewed openaccess journal that focuses on the optimal treatment of infection (bacterial, fungal and viral) and the development and institution of preventive strategies to minimize the development and spread of resistance. The journal is specifically concerned with the epidemiology of antibiotic
18. Silva M, Poo J, Wagner F, et al. A randomised trial to compare the pharmacokinetic, pharmacodynamic, and antiviral effects of peginterferon alfa- $2 \mathrm{~b}$ and peginterferon alfa- $2 \mathrm{a}$ in patients with chronic hepatitis C (COMPARE). J Hepatol. 2006;45:204.

19. Di Bisceglie AM, Ghalib RH, Hamzeh FM, Rustgi VK. Early virologic response after peginterferon alpha-2a plus ribavirin or peginterferon alpha-2b plus ribavirin treatment in patients with chronic hepatitis $\mathrm{C}$. J Viral Hepat. 2007;14:721.

20. Laguno M, Cifuentes C, Murillas J, et al. Randomized trial comparing pegylated interferon alpha- $2 \mathrm{~b}$ versus pegylated interferon alpha- $2 \mathrm{a}$, both plus ribavirin, to treat chronic hepatitis $\mathrm{C}$ in human immunodeficiency virus patients. Hepatology. 2009;49:22.

21. McHutchison JG, Lawitz EJ, Shiffman ML, et al. Peginterferon Alfa-2b or Alfa-2a with Ribavirin for Treatment of Hepatitis C Infection. NEngl J Med. 2009;361:580-594.

22. Ascione A, De Luca M, Tartaglione MT, et al. Peginterferon Alfa-2a Plus Ribavirin is More Effective than Peginterferon Alfa-2b Plus Ribavirin for Treating Chronic Hepatitis C Virus Infection. Gastroenterology. 2010;138:116-122.

23. Zeuzem $\mathrm{S}$. Heterogeneous virologic response rates to interferon-based therapy in patients with chronic hepatitis $\mathrm{C}$ : who responds less well? Ann Intern Med. 2004;140:370.

24. Davis GL, Wong JB, McHutchison JG, Manns MP. Early virologic response to treatment with peginterferon alfa- $2 \mathrm{~b}$ plus ribavirin in patients with chronic hepatitis C. Hepatology. 2003;38:645.

25. Ferenci P, Fried MW, Shiffman ML, et al. Predicting sustained virological responses in chronic hepatitis $\mathrm{C}$ patients treated with peginterferon alfa-2a (40 KD)/ribavirin. J Hepatol. 2005;43:425.

26. Ferenci P, Laferl H, Scherzer TM, et al. Peginterferon alfa-2a and ribavirin for 24 weeks in hepatitis $\mathrm{C}$ type 1 and 4 patients with rapid virological response. Gastroenterology. 2008;135:451.

27. Krawitt EL, Ashikaga T, Gordon SR, et al. Peginterferon alfa-2b and ribavirin for treatment-refractory chronic hepatitis C. J Hepatol. 2005;43:243.

28. McGovern BH. Hepatitis in the HIV infected patient. Acquir Immure Defic Syndr. 2007;45:47-56.

29. Blackard J, Smeaton L, Hiasa Y, et al. Detection of hepatitis C virus in serum and peripheral blood mononuclear cells from $\mathrm{HCV}$ monoinfected and HCV/HIV co infected persons. Infect Dis. 2005;192:258-265.

30. Soriano V. Treatment of chronic hepatitis $\mathrm{C}$ in HIV positive individuals: Selection of candidates. Hepatol. 2006;44(suppl):S44-S48.

31. Torriani FJ, Rodriguez-Torres M, Rockstroh JK, et al. Peginterferon Alfa-2a plus Ribavirin for Chronic Hepatitis C Virus Infection in HIVInfected Patients. New Engl Med. 2004;351:438-450.

32. Milazzo L, Caramma I, Mazzali C, et al. Fluvastatin as an adjuvant to pegylated interferon and ribavirin in HIV/hepatitis $\mathrm{C}$ virus genotype 1 co-infected patients: an open-label randomized controlled study. Antimicrob Chemother. 2010;65:735-740.

33. Huang CF, Yang JF Dai CY, et al. Efficacy and Safety of Pegylated Interferon Combined with Ribavirin for the Treatment of Older Patients with Chronic Hepatitis C. Infect Dis. 2010;201:751-759.

34. Liu-Yong G, Kozal MJ. Hepatitis C protease and polymerase inhibitors in development. AIDS Patient Care STDS. 2008;22(6):449-457.

\section{Dovepress}

resistance and the mechanisms of resistance development and diffusion in both hospitals and the community. The manuscript management system is completely online and includes a very quick and fair peerreview system, which is all easy to use. Visit http://www.dovepress.com/ testimonials.php to read real quotes from published authors. 